\title{
Low systolic blood pressure values, renal resistive index measurement and glomerular filtration rate in a non-dialysis dependent chronic kidney disease population
}

\author{
Simone Brardi ${ }^{1}$, Gabriele Cevenini ${ }^{2}$ \\ ${ }^{1}$ Hemodialysis Unit, S. Donato Hospital, Arezzo, Italy; \\ ${ }^{2}$ Department of Medical Biotechnologies, University of Siena, Italy.
}

\begin{abstract}
Summary Objective: A longitudinal prospective case control study was organized to explore the relationships between glomerular filtration rate (GFR), renal resistive index (RRI) and blood pressure values in a non-dialysis dependent adult population affected by chronic kidney disease and exposed to low systolic blood pressure (SBP) values. Material and methods: The study sample (54 patients: 31 males and 23 females with an average age of $61.7 \pm 19.2$ years) was randomly selected from a population of adult non-dialysis dependent patients that scored a SBP $<100 \mathrm{mmHg}$ at the medical examination. The patients were equally divided in two groups defined by the presence and absence of chronic kidney disease, (i.e. a GFR less or greater than $60 \mathrm{ml} / \mathrm{min} / 1.73 \mathrm{~m}^{2}$, respectively). Patients were submitted to a full therapeutic and dietetic intervention to correct the hypotension until reaching a steady SBP > $100 \mathrm{mmHg}$.

Results: In the group with chronic renal disease, the comparison between the data recorded with $\mathrm{SBP}<100 \mathrm{mmHg}(\mathrm{tO})$ and those detected with $S B P \geq 100 \mathrm{mmHg}(t 1)$ showed a statistically significant decrease of serum creatinine as well as an increase of GFR (mean serum creatinine t0 - serum creatinine t1: 0.194 $\pm 0.35, p<0.01$; mean GFR t0 - GFR t1: $-4.615 \pm 8.8, p<$ $0.013)$. There was also a statistically significant reduction of the RRI (mean right kidney RRI t0 - mean right kidney RRI t1: $+0.082 \pm 0.03, p<0$; mean left kidney RRI to - mean left kidney RRI t1: $0.076 \pm 0.03, p<0$ ).

Conclusion: We concluded that, in CKD, when aorta is stiffed, a decrease of SBP can limit the renal perfusion that, in this condition, is mostly dependent by stroke volume, causing an increase of RRI and a decrease of GFR that we suppose as reversible with the restoration of $S B P$.
\end{abstract}

KEY WORDS: Longitudinal prospective case control study; Chronic kidney disease; Renal Doppler ultrasonography; Renal resistive index; Low systolic blood pressure.

Submitted 1 November 2018; Accepted 15 December 2018

\section{INTRODUCTION}

Recently it has emerged that in a non-dialysis dependent population suffering from chronic kidney disease (CKD) and subjected to conventional therapeutic and dietary treatment there is a statistically significant correlation between reduction of renal resistive index (RRI) (which if high, i.e. $\geq 0.7$, represent an unfavorable prognostic index of renal disease progression) and reduction of systolic blood pressure (SBP) (1).

While it is known what should be the normal range for resistance indices $(0.47-0.70)$ (2), the same cannot be said about the ideal thresholds for arterial pressure.

In this regard, although there is consensus in setting a target for blood pressure lower than 140/90 $\mathrm{mmHg}$ for most individuals, according to some Authors the achievement of blood pressure values lower than 130/80 $\mathrm{mmHg}$ could guarantee an improvement of the clinical outcome compared to the 140/90 $\mathrm{mmHg}$ threshold in adults with chronic kidney disease $(3,4)$. However, there is no consensus on what may be a minimum threshold for the same blood pressure and this despite it being well known how damage can occur if intensive blood pressure treatment is implemented in patients with chronic renal failure (3). In particular, in a cohort of over 650.000 American veterans suffering from chronic kidney disease, patients who had an "ideal" blood pressure $(<130 / 80 \mathrm{mmHg}$ ) showed an increase in mortality due to the inclusion in this group of individuals with low systolic and/or diastolic arterial values. This association was confirmed both in diabetics and in non diabetics, or in those who had microalbuminuria or not (5).

We organized a longitudinal prospective case control study with the intent to explore the relationships between renal function, renal resistive index (RRI) (used as a monitoring tool) and blood pressure values in a nondialysis dependent adult population affected by chronic kidney disease and exposed to reduced systolic blood pressure values ( $\mathrm{SBP}<100 \mathrm{mmHg}$ ).

\section{Materials AND METHOdS}

A longitudinal prospective case control type study was planned.

The study sample (54 patients: 31 males and 23 females with an average age of $61.7 \pm 19.2$ years) was randomly selected from a population of adult non-dialysis dependent patients attending the outpatient nephrology clinic of San Donato Hospital in Arezzo that scored a systolic blood pressure $<100 \mathrm{mmHg}$ at medical examination.

The study population was initially affected by hyperten- 
sion and/or diabetes mellitus and/or chronic glomerulonephritis with or without chronic kidney disease or albuminuria. Patients with obstructive uropathy, acute glomerulonephritis, tubulointerstitial renal diseases,

Table 1.

Baseline characteristics of the population enrolled.

\begin{tabular}{|c|c|c|c|c|c|}
\hline & $\begin{array}{l}\text { GFR group } \\
\left(\mathrm{ml} / \mathrm{min} / 1.73 \mathrm{~m}^{2}\right)\end{array}$ & $\mathbf{N}^{0}$ & Mean & $\begin{array}{l}\text { Standard } \\
\text { deviation }\end{array}$ & $\begin{array}{c}\text { Mean } \\
\text { standard error }\end{array}$ \\
\hline Age to (years) & $\begin{array}{l}<60 \\
>60\end{array}$ & $\begin{array}{l}26 \\
25\end{array}$ & $\begin{array}{l}69.35 \\
54.36\end{array}$ & $\begin{array}{l}18.974 \\
16.671\end{array}$ & $\begin{array}{l}3.721 \\
3.334\end{array}$ \\
\hline Height (cm) & $\begin{array}{l}<60 \\
>60\end{array}$ & $\begin{array}{l}26 \\
24\end{array}$ & $\begin{array}{c}164.038 \\
167.5\end{array}$ & $\begin{array}{c}10.5356 \\
8.3406\end{array}$ & $\begin{array}{l}2.0662 \\
1.7025\end{array}$ \\
\hline Weight t0 (kg) & $\begin{array}{l}<60 \\
>60\end{array}$ & $\begin{array}{l}26 \\
24\end{array}$ & $\begin{array}{l}73.146 \\
76.817\end{array}$ & $\begin{array}{l}12.2153 \\
15.1616\end{array}$ & $\begin{array}{l}2.3956 \\
3.0948\end{array}$ \\
\hline Body mass index t0 $\left(\mathrm{kg} / \mathrm{m}^{2}\right)$ & $\begin{array}{l}<60 \\
>60\end{array}$ & $\begin{array}{l}26 \\
24 \\
\end{array}$ & $\begin{array}{c}27.1753 \\
27.25421 \\
\end{array}$ & $\begin{array}{l}3.6804 \\
4.3580 \\
\end{array}$ & $\begin{array}{c}0.721794187 \\
0.88958826 \\
\end{array}$ \\
\hline creatinine to (mg/dl) & $\begin{array}{l}<60 \\
>60\end{array}$ & $\begin{array}{l}26 \\
25\end{array}$ & $\begin{array}{l}1.7892 \\
0.9456\end{array}$ & $\begin{array}{l}0.6175 \\
0.1712\end{array}$ & $\begin{array}{l}0.12112 \\
0.03424\end{array}$ \\
\hline GFR to $\left(\mathrm{ml} / \mathrm{min} / 1.73 \mathrm{~m}^{2}\right)$ & $\begin{array}{l}<60 \\
>60\end{array}$ & $\begin{array}{l}26 \\
25\end{array}$ & $\begin{array}{l}38.615 \\
82.96\end{array}$ & $\begin{array}{l}12.9648 \\
17.3505\end{array}$ & $\begin{array}{l}2.5426 \\
3.4701\end{array}$ \\
\hline proteinuria t0 (gr/24h) & $\begin{array}{l}<60 \\
>60\end{array}$ & $\begin{array}{l}25 \\
20\end{array}$ & $\begin{array}{c}0.2256 \\
0.31645\end{array}$ & $\begin{array}{l}0.3884 \\
0.5184\end{array}$ & $\begin{array}{l}0.0776993 \\
0.1159197\end{array}$ \\
\hline Hba1c t0 (\%) & $\begin{array}{l}<60 \\
>60\end{array}$ & $\begin{array}{l}6 \\
4\end{array}$ & $\begin{array}{c}6.75 \\
5.975\end{array}$ & $\begin{array}{l}0.5089 \\
0.5123\end{array}$ & $\begin{array}{l}0.2078 \\
0.2562\end{array}$ \\
\hline$\overline{\mathrm{SBP}}$ t0 (mmHg) & $\begin{array}{l}<60 \\
>60\end{array}$ & $\begin{array}{l}26 \\
25\end{array}$ & $\begin{array}{l}90.115 \\
91.6\end{array}$ & $\begin{array}{l}5.2484 \\
4.7697\end{array}$ & $\begin{array}{l}1.0293 \\
0.9539\end{array}$ \\
\hline DBP t0 (mmHg) & $\begin{array}{l}<60 \\
>60\end{array}$ & $\begin{array}{l}26 \\
25\end{array}$ & $\begin{array}{c}58.192 \\
66.72\end{array}$ & $\begin{array}{l}9.9881 \\
6.9072\end{array}$ & $\begin{array}{l}1.9588 \\
1.3814\end{array}$ \\
\hline right kidney RRI t0 & $\begin{array}{l}<60 \\
>60\end{array}$ & $\begin{array}{l}25 \\
23\end{array}$ & $\begin{array}{c}0.746 \\
0.6265\end{array}$ & $\begin{array}{l}0.06212 \\
0.05407\end{array}$ & $\begin{array}{l}0.01242 \\
0.01127\end{array}$ \\
\hline left kidney RRI t0 & $\begin{array}{l}<60 \\
>60\end{array}$ & $\begin{array}{l}24 \\
20\end{array}$ & $\begin{array}{c}0.7413 \\
0.63\end{array}$ & $\begin{array}{l}0.06306 \\
0.07138\end{array}$ & $\begin{array}{l}0.01287 \\
0.01596\end{array}$ \\
\hline right kidney diameter t0 (mm) & $\begin{array}{l}<60 \\
>60\end{array}$ & $\begin{array}{l}26 \\
23\end{array}$ & $\begin{array}{c}99.538 \\
109.478\end{array}$ & $\begin{array}{l}12.7349 \\
13.5139\end{array}$ & $\begin{array}{l}2.4975 \\
2.8178\end{array}$ \\
\hline left kidney diameter to (mm) & $\begin{array}{l}<60 \\
>60\end{array}$ & $\begin{array}{l}24 \\
22\end{array}$ & $\begin{array}{l}103.958 \\
116.045\end{array}$ & $\begin{array}{l}12.2065 \\
12.0217\end{array}$ & $\begin{array}{l}2.4916 \\
2.563\end{array}$ \\
\hline age t1 (years) & $\begin{array}{l}<60 \\
>60\end{array}$ & $\begin{array}{l}26 \\
25\end{array}$ & $\begin{array}{l}68.46 \\
53.04\end{array}$ & $\begin{array}{c}19.59 \\
16.352\end{array}$ & $\begin{array}{c}3.842 \\
3.27\end{array}$ \\
\hline Weight t1 (kg) & $\begin{array}{l}<60 \\
>60\end{array}$ & $\begin{array}{l}25 \\
23\end{array}$ & $\begin{array}{c}74.44 \\
78.448\end{array}$ & $\begin{array}{l}13.4028 \\
15.3239\end{array}$ & $\begin{array}{l}2.6806 \\
3.1952\end{array}$ \\
\hline Body mass index t1 $\left(\mathrm{kg} / \mathrm{m}^{2}\right)$ & $\begin{array}{l}<60 \\
>60\end{array}$ & $\begin{array}{l}25 \\
23 \\
\end{array}$ & $\begin{array}{l}27.62463 \\
27.65597 \\
\end{array}$ & $\begin{array}{l}4.0364 \\
4.3396 \\
\end{array}$ & $\begin{array}{l}0.807297865 \\
0.904875025 \\
\end{array}$ \\
\hline creatinine t1 (mg/dl) & $\begin{array}{l}<60 \\
>60\end{array}$ & $\begin{array}{l}26 \\
25\end{array}$ & $\begin{array}{c}1.5946 \\
0.978\end{array}$ & $\begin{array}{l}0.43552 \\
0.17769\end{array}$ & $\begin{array}{l}0.08541 \\
0.03554\end{array}$ \\
\hline GFR t1 $\left(\mathrm{ml} / \mathrm{min} / 1.73 \mathrm{~m}^{2}\right)$ & $\begin{array}{l}<60 \\
>60\end{array}$ & $\begin{array}{l}26 \\
25\end{array}$ & $\begin{array}{c}43.231 \\
81.4\end{array}$ & $\begin{array}{c}13.5685 \\
21\end{array}$ & $\begin{array}{c}2.661 \\
4.2\end{array}$ \\
\hline proteinuria t1 (gr/24h) & $\begin{array}{l}<60 \\
>60\end{array}$ & $\begin{array}{l}22 \\
18\end{array}$ & $\begin{array}{l}0.323682 \\
0.342389\end{array}$ & $\begin{array}{l}0.5561 \\
0.5020\end{array}$ & $\begin{array}{c}0.118575 \\
0.1183385\end{array}$ \\
\hline Hba1c t1(\%) & $\begin{array}{l}<60 \\
>60\end{array}$ & $\begin{array}{l}5 \\
2\end{array}$ & $\begin{array}{l}6.34 \\
6.05\end{array}$ & $\begin{array}{l}0.5727 \\
0.2121\end{array}$ & $\begin{array}{c}0.2561 \\
0.15\end{array}$ \\
\hline SBP t1 (mmHg) & $\begin{array}{l}<60 \\
>60\end{array}$ & $\begin{array}{l}26 \\
25\end{array}$ & $\begin{array}{c}114.654 \\
109.44\end{array}$ & $\begin{array}{c}10.2526 \\
7.6381\end{array}$ & $\begin{array}{l}2.0107 \\
1.5276\end{array}$ \\
\hline DBP t1 (mmHg) & $\begin{array}{l}<60 \\
>60\end{array}$ & $\begin{array}{l}26 \\
25\end{array}$ & $\begin{array}{c}74.154 \\
76.84\end{array}$ & $\begin{array}{c}13.5135 \\
8.0658\end{array}$ & $\begin{array}{l}.6502 \\
1.6132\end{array}$ \\
\hline right kidney RRI t1 & $\begin{array}{l}<60 \\
>60\end{array}$ & $\begin{array}{l}24 \\
23\end{array}$ & $\begin{array}{l}0.6638 \\
0.6348\end{array}$ & $\begin{array}{l}0.06309 \\
0.07391\end{array}$ & $\begin{array}{l}0.01288 \\
0.01541\end{array}$ \\
\hline left kidney RRI t1 & $\begin{array}{l}<60 \\
>60\end{array}$ & $\begin{array}{l}24 \\
22\end{array}$ & $\begin{array}{c}0.665 \\
0.6355\end{array}$ & $\begin{array}{l}0.06164 \\
0.07645\end{array}$ & $\begin{array}{c}0.01258 \\
0.0163\end{array}$ \\
\hline right kidney diameter $\mathrm{t} 1(\mathrm{~mm})$ & $\begin{array}{l}<60 \\
>60\end{array}$ & $\begin{array}{l}26 \\
24\end{array}$ & $\begin{array}{c}101 \\
110.417\end{array}$ & $\begin{array}{l}13.1088 \\
14.7852\end{array}$ & $\begin{array}{c}2.5708 \\
3.018\end{array}$ \\
\hline left kidney diameter t1 (mm) & $\begin{array}{l}<60 \\
>60\end{array}$ & $\begin{array}{l}24 \\
23\end{array}$ & $\begin{array}{c}104.458 \\
116.13\end{array}$ & $\begin{array}{l}12.7381 \\
11.8372\end{array}$ & $\begin{array}{l}2.6002 \\
2.4682\end{array}$ \\
\hline
\end{tabular}

renal artery stenosis and malignant disease were excluded. Pregnant women and children were also excluded. The total number of patients was selected to be equally divided in two groups defined by the presence (case) and absence (control) of chronic renal disease, defined by a glomerular filtration rate (GFR) less or greater than $60 \mathrm{ml} / \mathrm{min} / 1.73 \mathrm{~m}^{2}$, respectively.

The average GFR (calculated by the CKD EPI equation) (6), was $38.5 \pm 12.7$ $\mathrm{ml} / \mathrm{min} / 1.73 \mathrm{~m}^{2}$ for case group and 82.3 $\pm 17 \mathrm{ml} / \mathrm{min} / 1.73 \mathrm{~m}^{2}$ for control group (Table 1). A prevalence of male gender was observed in both study and control groups. The anthropometric parameters (weight, height, age, sex and body mass index) did not differ statistically (at a significance level of 95\%) in the two groups (Table 1). At the time of enrollment a written informed consent was obtained by all the patients.

After the enrollment the patients were submitted to a complete medical examination, comprehensive of the recording of weight and height. A measure of blood pressure was taken with a mercury sphygmomanometer applied around each patient's non-dominant arm after the patient had rested for 15 minutes in a sitting position and with his/her arm placed at the level of the heart. Two consecutives blood pressure recordings, taken at 5 minute interval, were averaged to provide clinic systolic and diastolic blood pressure values.

Blood and urine samples were obtained for measurement of serum creatinine, glycated hemoglobin and 24-hour urinary albumin excretion. Finally, renal Doppler ultrasonography examination was carried out by the same nephrologist experienced in ultrasound examination using the same ultrasound device that was a Logiq S7 (GE Medical Systems Italy S.P.A. Milan, Italy) sonographic system equipped with 3 to $5 \mathrm{Mhz}$ transducers. Doppler signals were obtained from the interlobar arteries from the upper, middle and lower third of both kidneys and resistive index was calculated as the average of 6 measurements (3 from each of the 2 kidneys) taken for each patient. The Doppler angle was chosen as close to $0^{\circ}$ as possible and special care was taken not to compress the kidney and not to have the patient performing Valsalva maneuver because both of them can increase the renal resistive index value. We recorded also the diameters in the longitudinal axis of each kidney and the cortical thickness of each kidney, measured in the portion closer to the upper pole and the lower pole of the same kidney. 
We recorded any data about the therapeutic and dietary treatment of the patients with special regard to the use of drugs that may interfere with the RRI determinations such as angiotensin II receptor blockers (ARBs) or angiotensin converting enzyme (ACE) inhibitors and beta blockers and the use or not of an hyposodic, hypoproteic, hypoglicemic as well as hypocaloric diet.

Then the patients were submitted to a full therapeutic and dietetic intervention to correct the hypotension by a reduction of dosage or removal of hypotensive drugs.

After a variable interval period, depending from the time necessary to recovery a steady systolic blood pressure > $100 \mathrm{mmHg}$ for on average one year, patients were submitted again to a new medical examination comprehensive of the recording of weight and clinic blood pressure values with the same modalities above mentioned. Values of serum creatinine, glycated hemoglobin and 24hour urinary albumin excretion were collected again and a new renal Doppler ultrasonography was carried out by the above mentioned nephrologist experienced in ultrasound investigation by using the same ultrasound device. All data relating to the therapeutic and dietary treatment used by the patients were recorded again.

\section{Statistical analysis}

Descriptive statistics included mean and standard deviation for quantitative data, and frequency count and percentage for qualitative data. For quantitative variables, groups were compared with the Student $\mathrm{t}$ test for unpaired data or the Mann-Whitney rank test, respectively depending on the normal or non-normal distribution of population data. The normality was assessed by applying the Kolmogorov-Smirnov test to sample data. Comparisons between $\mathrm{t} 0$ and $\mathrm{t} l$ were made using the Student $t$ test for paired data or the Wilcoxon rank test for normal or non-normal data respectively. For dichotomous qualitative variables, frequency counts between groups were compared using the Fisher exact test applied to $2 \times 2$ contingency data. A statistical significance level of $95 \%$ was chosen for all statistical analyses $(\mathrm{p}<0.05)$ that were performed using SPSS software, version 10 .

\section{RESULTS}

Considering the two groups with GFR $<60$ and GFR $\geq$ $60 \mathrm{ml} / \mathrm{min} / 1.73 \mathrm{~m}^{2}$ separately, within the group with GFR $<60 \mathrm{ml} / \mathrm{min} / 1.73 \mathrm{~m}^{2}$, the comparison between the data recorded with systolic blood pressure $(\mathrm{SBP})<100$ $\mathrm{mmHg}(\mathrm{t} 0)$ and those detected with SBP $\geq 100 \mathrm{mmHg}$ (t1) showed that, passing from time 0 to time 1 , there was a statistically significant increase of body weight (BW) (mean BWt0 - BWt1: $-1.428 \pm 3.2 ; \mathrm{p}<0.04$ ), although the clinical significance of this observation was not very relevant as it was about $2 \%$. A statistically and clinically significant decrease of serum creatinine as well as a statistically and clinically significant increase of the glomerular filtrate rate was observed (mean creatinine t0 - creatinine tl: $0.194 \pm 0.35 ; \mathrm{p}<0.01$; equal to a reduction of approximately $11 \%$; mean GFR t0 - GFR t1: $4.615 \pm 8.8, \mathrm{p}<0.013$, equal to an increase of over $12 \%)$. A statistically and clinically significant decrease of the renal resistive index (RRI) was also observed (mean right kidney RRI t0 - mean right kidney RRI tl: + 0.082 $\pm 0.03, \mathrm{p}<0$, equal to a $10.8 \%$ reduction. Mean left kidney RRI t0 - mean left kidney RRI t1: $0.076 \pm 0.03$, $\mathrm{p}<0$, equal to a reduction of $10.2 \%$ ).

Comparison for paired data also identified a statistically significant reduction of the glycated hemoglobin data, to which, however, given the small number of diabetics on the total ( 6 out of 27 equal to about $22 \%$ of the total), it was not possible to attribute a clinical relevance.

Within the control group (GFR $\geq 60 \mathrm{ml} / \mathrm{min} / 1.73 \mathrm{~m}^{2}$ ) there was no statistically significant variation between times $t 0$ and $t 1$ except, of course, the increase in the arterial pressure values (systolic and diastolic), a finding that was also found in the cases (GFR $<60 \mathrm{ml} / \mathrm{min} / 1.73 \mathrm{~m}^{2}$ ) confirming the respect of the working hypothesis.

Finally considering the two groups together, the comparison for all the variables between time zero and time 1 confirmed a statistically significant increase of body weight as well as a statistically significant decrease in serum creatinine levels and a statistically significant reduction of the intrarenal arterial resistance indices of the right kidney and of the left kidney. In the comparison for paired data a statistically significant reduction of glycated hemoglobin was found for the entire population such as, both for the two groups separately.

The comparison of data from the two groups for all the variables, confirmed the quality of the above exposed observations by detecting a significant difference between groups for creatinine at both time intervals, GFR at both time intervals, right kidney RRI and left kidney RRI at time 0 as well as right kidney diameter and left kidney diameter at both time intervals.

\section{Discussion}

A unique feature of the kidney is that it is continually and passively perfused at high volume flow throughout systole and diastole. Its vascular resistance is very low so that in comparison to other vascular beds resistance is closer to input and characteristic impedance (7). It is therefore susceptible to upstream influences that may increase fluctuations of pressure and flow, whereas small vessels in other organs are protected by relatively intense vasoconstriction upstream (7).

In patients with chronic kidney disease (CKD) and endstage renal disease (ESRD) all epidemiological studies have clearly shown that an accelerated arterial and cardiac aging by atherosclerosis is characteristic of these populations. Atherosclerosis is a generalized arterial disease of the arterial intima characterized by the presence of plaque and occlusive arterial lesions. The functional consequence of these structural alterations is hardening/sclerosis of vessel walls (arteriosclerosis) and loss of compliance, that is increased stiffness.

When the arterial premature aging involves the aorta it stands out for an aortic stiffening and for the disappearance of stiffness/impedance gradients between the central and peripheral arteries. These changes have a double impact: on the heart, upstream, with high systolic and pulse pressures and decreasing diastolic pressure, increased cardiac afterload and arterial circumferential 
stress. All these factors promote left ventricular hypertrophy (LVH) which may evolve toward heart failure. Downstream, on renal and brain microcirculation, with decrease in glomerular filtration and cognitive functions (8). Proof of all this is the fact that strong associations between aortic stiffness and indicators of renal dysfunction (glomerular filtration rate and microalbuminuria) have been described such as with cognitive impairment and dementia besides (as previously mentioned), left ventricular hypertrophy and left ventricular dysfunction (8). Physiologically, the higher compliance of the aorta coupled with a progressively lower compliance in peripheral vessels creates a "stiffness gradient" that works as a "hydraulic filter" and acts to buffer pressure pulsations and their transmission to microcirculation and capillary network (principally in the main parenchymal organs such as the kidney and the brain). The more distensible the arterial wall (that is, the lower the stiffness) the smoother the provision of proper flow to peripheral tissues. When the aorta is rigid and cannot be stretched, the entire stroke volume flows through the arterial system and peripheral tissues only during systole with two consequences: intermittent flow and short capillary transit time with reduced metabolic exchanges (9).

Therefore we believe that, in such a condition, a reduce of the systolic arterial blood pressure, such as a SBP < $100 \mathrm{mmHg}$, can further and definitely limit the renal perfusion that is already damaged by lacking of a proper aortic buffer.

About the Doppler renal Resistive index (RRI) described by Pourcelot (10) ((peak sistolic velocity-end diastolic velocity)/peak sistolic velocity) we observe that RRI is a traditional index used as a measure of vascular resistance. A value of 0.60 is considered as a normal value for renal RRI, whereas 0.70 is usually considered the upper threshold of normal RRI in adults. Several factors have been described to influence Doppler renal arterial waveform and therefore the RRI as renal vascular compliance, central hemodynamics (especially arterial stiffness, blood pressure and heart rate), and other factors including age, underlying acute or chronic renal disease and drugs too (11). In this regard it is known that RRI decreases with use of renin angiotensin system (RAS) inhibitors, due to hemodynamic changes induced by these antihypertensive agents (12) while RRI, significantly and independently, increased with use of beta-blockers (13).

In the setting of an acute kidney injury the first clinical application of RRI was the detection of renal obstruction because renal vasoconstriction is believed to be a key factor in the pathophysiology of acute kidney obstruction. Platt et al had proposed that an RRI $\geq 0.7$ was in favor of an acute renal obstruction and may precede pyelocalicectasis (14). Afterwards in 91 patients with acute kidney injury (AKI), Platt et al. demonstrated that mean RRI was significantly higher in patients with persistent AKI than in patients with transient AKI (15). Lastly in a small number of patients with septic shock, Deruddre et al. have shown a significant decrease in renal RRI when increasing mean arterial pressure (MAP) with norepinephrine from 65 to $75 \mathrm{mmHg}$. This study suggests that Doppler renal ultrasound may help to determine in each patient the optimal MAP for renal tissue perfusion and may be a relevant end point to titrate the hemodynamic treatment in septic shock (16). Accordingly, we believe that RRI may be used as a noninvasive and repeatable tool to assess changes in renal perfusion and it may be useful to determine the optimal therapeutic/preventive modalities for kidney perfusion at the bedside (11).

\section{Conclusions}

On the basis of all the above mentioned, we therefore believe that, when in CKD the aorta is stiffed and cannot be stretched, a decrease of the systolic arterial blood pressure, even temporary, can limit the renal perfusion that, in this condition, it is mostly (or entirely) a function of the stroke volume, causing an increase of the RRI and a reduction of the glomerular filtration rate as proven by this paper.

This scientific work shows that reduced systolic arterial pressure values (i.e. SBP $<100 \mathrm{mmHg}$ ) have an effect of worsening of renal function only when there is already a pre-existent significant impairment of the GFR (such as a GFR $<60 \mathrm{ml} / \mathrm{min} / 1.73 \mathrm{~m} \wedge$ 2) and not when a similar kidney damage is not present. However we believe that, since this decrease in renal function is a function of reduced systolic arterial pressure values, the restoration of the systolic pressure may recover the decrease of renal function that therefore can be considered reversible.

These observations appear congruent with what has already been reported by Judd et al. and Kovesdy et al. (3, 5) who, inspired by the association of low arterial pressure values with an increase in mortality, warns that "lowering SBP to the strict limits recommended by current guidelines (i.e. $\mathrm{SBP}<130 \mathrm{mmHg}$ or even lower) in patients with CKD (at the expense of lowering DBP below approximately $70 \mathrm{mmHg}$ may be deleterious".

Above all, the data of this study are fully supported by the results of the SPRINT trial (17) which showed as an intensive blood pressure control (i.e. SBP $<120 \mathrm{mmHg}$ ) produces a significant cardiovascular benefit in high-risk patients with hypertension at the price of an higher risk of hypotension, syncope, and accelerated reductions in GFR.

In fact in the SPRINT trial, acute kidney injury or acute renal failure occurred more frequently in the intensively treated group than in the standard-treated group and the Authors of this trial believe that the differences in adverse renal outcomes may be related to a reversible intrarenal hemodynamic effect of the greater reduction in blood pressure.

Furthermore the Authors of the SPRINT trial, as the Authors of the present paper, believe that with the currently available data, there is no evidence of substantial permanent kidney injury associated with a treatment with the goal of lower systolic blood-pressure although the possibility of a long-term adverse renal outcome cannot be excluded (17).

\section{REFERENCES}

1. Brardi S, Cevenini G, Giovannelli V, Romano G. Longitudinal prospective observational type study about determinants of renal resistive index variations in chronic renal failure patients treated 
with conventional medical and dietetic therapy. Arch Ital Urol Androl. 2017; 89, 4.

2. Lubas A, Kade G, Niemczyk S. Renal resistive index as a marker of vascular damage in cardiovascular diseases. Int Urol Nephrol. 2014; 46:395-402.

3. Judd E, Calhoun DA. Management of hypertension in CKD: beyond the guidelines. ADV Chronic Kidney Dis. 2015; 22:116-122.

4. Taler SJ, Agarwal R, Bakris GL et al. KDOQI US commentary on the 2012 KDIGO clinical practice guideline for management of blood pressure in CKD. Am J Kidney Dis. 2013; 62:201-213.

5. Kovesdy CP, Bleyer AJ, Molnar MZ, et al. Blood Pressure and Mortality in US Veterans with Chronic Kidney Disease. Ann Intern Med. 2013; 159:233-242.

6. Levey AS, Stevens LA, et al. A new equation to estimate glomerular filtration rate. Ann Intern Med. 2009; 150:604-612.

7. O'Rourke MF, Safar ME. Relationship between aortic stiffening and microvascular disease in brain and kidney cause and logic of therapy. Hypertension. 2005; 46:200-204.

8. London G, Covic A. Goldsmith D, et al. Arterial aging and arterial disease: interplay between central hemodynamics, cardiac work, and organ flow-implications for CKD and cardiovascular disease. Kidney Int Sup. 2011; 1:10-12.

9. Briet $M$, Boutouyrie $P$, Laurent $S$, et al. Arterial stiffness and pulse pressure in CKD and ESRD. Kidney Int. 2012; 82:388-400.

10. Pourcelot L. Applications cliniques de l'examen Doppler transcutanè. In Peronneau P (ed). Velocimetrie ultrasonore Doppler.
Paris. Seminare Institut National de la Santè et de la Recherche Medicale. 1975; pp 213-40.

11. Le Dorze M., Bouglè A, Deruddre S, et al. Renal Doppler ultrasound: a new tool to assess renal perfusion in critical illness. Shock 2012; 37:360-365

12. Leoncini G, Martinoli $C$, Viazzi F, et al. Change in renal resistive index and urinary albumin excretion in hypertensive patients under long-term treatment with lisinopril and nifedipine GITS. Nephron. 2002; 90:169-173.

13. Kuznetsova T, Cauwenberghs N, Knez J, et al. Doppler indexes of left ventricular systolic and diastolic flow and central pulse pressure in relation to renal resistive index. Am J Hypertens. 2015; 28:535-45

14. Platt JF, Rubin JM, Ellis JH. Acute renal obstruction: evaluation with intrarenal duplex Doppler and conventional US. Radiology. 1993; 186:685.

15. Platt JF, Rubin JM, Ellis JH. Acute renal failure: possible role of duplex Doppler US in distinction between acute prerenal failure and acute tubular necrosis. Radiology. 1991; 179:419.

16. Deruddre S, Cheisson G, Mazoit JX et al. Renal arterial resistance in septic shock: effects of increasing mean arterial pressure with norepinephrine on the renal resistive index assessed with Doppler ultrasonography. Intensive Care Med. 2007; 33:1557.

17. The SPRINT Research Group. A randomized trial of intensive versus standard blood-pressure control. N Engl J Med. 2015; 373:2103-2116

\section{Correspondence}

Simone Brardi, MD (Corresponding Author)

Hemodialysis Unit, S. Donato Hospital, Arezzo, Italy

Gabriele Cevenini, MD

Department of Medical Biotechnologies, University of Siena, Italy 